\title{
Taking the wrong turn? Re-examining the potential for practice approaches in archaeology
}

Andrew Gardner (UCL Institute of Archaeology)

Andrew is Senior Lecturer in the Archaeology of the Roman Empire at the UCL Institute of Archaeology. His work explores themes of materiality, temporality and social change on the Roman frontiers, and the contemporary politics of archaeology, particularly in Brexit Britain.

\begin{abstract}
Is the 'material' or 'ontological' turn a major new paradigm in archaeological theory? Or is it another iteration of the cycle of piecemeal innovation which has created a very fragmented discipline? While there are insights from recent scholarship in this vein which are certainly important, this paper will err toward the latter view. Even though 'symmetrical' and other object-agency approaches are still growing in mainstream archaeological debate, much of the source literature upon which they draw has been around for several decades, and accumulated a fair amount of critique. At the very least, therefore, we need to learn from the way the materiality debate is playing out in other sub-fields. Beyond that, I will argue, we should go back to the turn before this one - the practice turn - and explore that road a bit more thoroughly, if we are to find the most useful approaches to develop in the future.
\end{abstract}

\section{The many 'turns' of archaeology: vitality or fragmentation?}

At the beginning of the third decade of the $21^{\text {st }}$ century, archaeology is a discipline which is in a vulnerable place. Insofar as it is significant at all in a world dealing with the myriad consequences of the Covid-19 pandemic, and facing a climate catastrophe later this century, the past seems just as likely to be mobilised for competing nationalist discourses as it was a century ago. In other contexts, the remains of the past are also destroyed or looted almost as freely as they have ever been. These pressing concerns have made the concept of 'heritage' one of the major areas of growing disciplinary debate, while the traditional themes of archaeological theory and practice, dealing with the excavation and interpretation of material culture, have diminished in relative prominence. Even if, 40-odd years ago, the disputes between processual and post-processual archaeologists were neither as all-consuming or as polarising as they have come to seem in hindsight, the nature of archaeological discourse has undoubtedly shifted. It is difficult to disagree with Mizoguchi's (2015) assessment of the high degree of fragmentation in archaeological thought, concomitant with the rise of globalisation, 
to which trend the academic and other centres of the production of archaeological thinking are closely connected (cf. Rosenzweig 2020). One of the chief questions to be pursued in this paper is whether post-humanist approaches offer remedy to this situation, or derive from it, and perhaps exacerbate it; from this, the question of how to most effectively mobilise archaeology naturally flows.

In reflecting on the broad patterns in the development of theoretical debate in our discipline, I am not emphasising particular flaws (or benefits) of post-humanist approaches, which are more than sufficiently covered in other papers in this collection. What I am seeking to do is to place the emergence of this approach in some context, and from that argue that there are other perspectives, which seem to have been discarded, which are more suitable for archaeology to speak meaningfully to contemporary concerns. Fragmentation characterises that context, and it has been developing within archaeological theory for a long time. Our discipline is sufficiently diverse in the problems presented by the varying evidence for human life across the globe that it has never been a particularly coherent one, as David Clarke recognised, for his time, a generation ago (1973). The New Archaeology promised more unity, as indeed is being offered again with the influx of new scientific methods into archaeology right now (Kristiansen 2014; cf. Nilsson Stutz 2018), but at least in the former case that promise was not fulfilled. The disagreements between various of the chief proponents of the New Archaeology (e.g. Binford 1981; Schiffer 1985; cf. Flannery 1982) show that this process was not just linked to the postprocessual critique, with its array of diverse inspirations, but was embedded within the flawed heart of the processual revolution. Since the 1980s, of course, such fragmentation has only increased, with the contradictions between different strands of post-processualism (e.g. Shanks 2008) begetting further branching approaches within the 'Interpretive' tradition, and an equally complex topography among those maintaining the 'Evolutionary' tradition (e.g. Bentley et al. 2008), alongside all kinds of further bifurcations and interactions between the different lineages of archaeological thought (cf. e.g. Hegmon 2003; Johnson 2006). While there have been attempts to explain this process itself using an evolutionary framework (O'Brien et al. 2005), I think it would make an ideal case-study for a structurationist account that explores the dynamic roles of researchers and institutions over time and considers the political forces driving us to keep seeking new theoretical directions. Suffice it to say here, though, that this background helps to situate the recent material/ontological turn and consider what it could, and what it cannot, do for our discipline.

And this is a key point; it is still 'our' discipline - a broad-based and increasingly inclusive one. The positive view of these developments is that we have succeeded in achieving 
a pluralistic, discursive disciplinary space which accommodates a wealth of intellectual strands and which is capable of regular renewal, without particularly undermining our ability to respect each other's identity as archaeologists (cf. Johnson 2020: 278-81). To return again to David Clarke, archaeology remains "what archaeologists do" (1973: 6). I would certainly adhere to this position. And yet, there remains a doubt that the divergences over the very subject of our discipline are becoming so great that not only are the dialogues within our field in jeopardy, but our ability to answer the calls of our time is seriously compromised. The question of whether we are the discipline of things, or of people, goes back to the early days of archaeology's loss of innocence (e.g. Wheeler 1954: 2). It took a good deal of effort to get to the point where knowledgeable human actors were allowed to take their place at the centre of archaeological interpretation (e.g. Hodder 1985; cf. Díaz de Liaño del Valle and FernándezGötz, this volume). Has their time already passed, just when we need to communicate to the world that history is not simply a parade of different ethnic groups whose rise and fall leads inevitably to the present, but was an open-ended reality which could have been otherwise? And have we, in the rapid turnover of ideas that has fuelled the fragmentation of the intellectual core of our discipline, seriously worked through all of the ways in which we might emancipate the people of the past from our reliance on the things that lead us to them? I have (Gardner 2003), and do, appreciate insights from the material/ontological turn about the role of the object-world in the development of human subjects, but I think we need to defend humanism in the present by securing the gains that were made in re-humanising archaeology in the 1980s and seeing through some of the ideas that helped us get there. In particular, the turn before the material turn - the practice turn - deserves deeper consideration as a way of understanding the interactions of people and things through the lens of action.

Before expanding on this in the second half of this contribution, some of the drawbacks of fragmentation need to be noted. Several other papers in this collection outline the key contours of broadly post-humanist approaches as they have been developing in archaeology for the last two decades or so, so there is no need here for me to recapitulate the key tenets of symmetrical archaeology, entanglement theory or assemblage theory - or potential problems with them (see also e.g. Johnson 2020: 151-4; Lindstrøm 2015; Ribeiro 2016, 2018; Van Dyke 2015). The diverse strands of the material turn (see esp. Crellin and Harris, this volume) all draw upon different bodies of work, often linked to key thinkers outside of archaeology in philosophy, Science and Technology Studies, anthropology, and so forth, as is entirely normal practice in theoretical archaeology. Paradoxically, though, at least some do so in service of shaping a supposedly distinctive vision of archaeology as the discipline of things (e.g. Olsen et 
al. 2012). This is an interesting situation, because while some of the material culture studies scholars in the influential school based in Anthropology at UCL were indeed archaeologists earlier in their careers, much of the other literature on the wider material turn in, say, sociology, does not make much reference to archaeology (e.g. Dant 1999; Matthewman 2011; Preda 1999) - again, a common enough phenomenon whereby archaeology imports but does not seem to export (cf. Lucas 2015). Moreover, the work of many of those influential writers in STS or other fields has already been subject to extensive discussion or critique before being adopted in archaeology (see e.g. Bloor 1999; Elam 1999; Jones 1996; Vandenberghe 2002), where that critique is often omitted from the debate. Again, this is not a problem confined to posthumanist approaches, and indeed can be seen as a trend since the 1960s, with approaches as diverse as logical positivism, critical theory and, indeed, practice theory, suffering from some degree of the same affliction. One solution would be to work at ideas for much longer before moving on to the next, spending more time on the interdisciplinary engagement necessary to calibrate their fit with archaeology more effectively, and that is what I argue below for practice theory. What is particularly ironic in the case of post-humanist approaches, though, is that archaeologists had just begun to move more fully from objects to people right at the time that the material turn started to developed in other disciplines, in the 1980s. To now be seduced by this material turn is, in my view, a move which actually takes archaeology backwards, and not forwards. Archaeology had been developing from material determinism to a more balanced view of the relations between things and people, thanks to the incorporation of social theory, and that direction is worth continuing with, as I believe it constitutes a position from which we can make real contributions to other fields, and wider debates across society.

\section{Back to the practice turn: relationality, interaction, and human agency}

Of course, that requires us to back-track to a turn we had already taken. Though perhaps not articulated explicitly as a 'practice turn' in the 1990s, the influence of Giddens' structuration theory and Bourdieu's theory of practice was at its peak then, prior to the critique which developed of the supposed deficiencies in the model of agency those theories deployed (see e.g. Dornan 2002; Gardner 2011 for overviews). While in many ways that period of archaeological thought was subject to the same problems I've just described, needing to better take on board the extensive critical literature surrounding structuration theory, for example, I also believe that a lot of the archaeological critique which developed into the ontological turn rested on over-simplified caricatures of the principles of structuration theory and related approaches. This much is revealed, indeed, in the way that so much of that debate was framed 
around problems with defining 'agency', when structuration theory was never just a theory of agency, and the whole idea of 'agency theory' is something of a misnomer (Gardner 2011; Joyce and Lopiparo 2005). Structuration, like other approaches within the practice tradition, is about relationships, and what those relationships do to define different kinds of entities over time and through action. The practice tradition is a deep and rich one, with roots in Marxism and in the much more neglected (in archaeology) school of Pragmatism, within which context theorists such as George Herbert Mead were talking about the social nature of objects and their role in the constitution of the self a century ago (e.g. Mead 2002; McCarthy 1984; Shalin 2000). It is also a living tradition which continues to develop in a wide range of disciplines (e.g. Nicolini 2012; Orlikowski 2000; Reckwitz 2002; Schatzki 2006; Simpson 2009). What it offers to archaeology is considerable (e.g. Fewster 2014; Lightfoot et al. 1998; Saitta 2003), in being able to both facilitate our understanding of material practices in the constitution of historicallyspecific agents and their societies, and also to understand our own disciplinary practice within contemporary organisations like universities. What is required to deliver on this promise is nothing more elaborate than patience. Yet patience is precisely what our condition of fragmentation discourages.

This, then, is where we need archaeologies that 'do work' (to borrow a Pragmatic principle) and do so over a prolonged period of time, engaging deep debate and deep research that must involve lots of people in collaboration. This of course involves the plurality of approaches which are current in archaeological thinking today, including post-humanist ones - not least because we often share a commitment to similar values (cf. Caraher 2019; Crellin and Harris, this volume) - yet in a new way of working which is not dismissive of previous traditions but is rather interested in their interactions and their undiscovered possibilities. The practice tradition has a strong claim to be part of such an enterprise, not least because it offers ways of actually informing the conduct of the enterprise itself, through theories of how communities of practice take shape (e.g. Wenger 1998; cf. Gardner 2016). More specifically, the practice turn achieved many of the things that advocates of the material turn have called for, without abandoning an ethical humanism, within which intentionality plays an important role (cf. Ribeiro 2018), nor surrendering the critical analysis of ideologies, present or past. The idea that humans emerge as distinctive because of their material relationships is neither new nor incompatible with 'humanist' notions of agency, structure and practice as the building blocks of an analytically-useful social theory. Indeed, Marx argued for much of that (cf. McGuire, this volume), and the insights of the likes of Mead, William James and Erving Goffman echo these points and have shaped what are, to me, some of the most interesting 
discussions of the material and historical constitution of human agency (e.g. Dunn 1997; Emirbayer and Mische 1998; Schatzki 2010; Shalin 2000). Placing practice at the heart of theory makes it relational, interactive, and dynamic, but does not give up on inequality, power or embodied selfhood.

In doing so, I believe that the practice tradition gives archaeology tools to work with, both in relation to the past, and the present. Rather than asking us to assume an eternal or universal type of human agent, it enables us to investigate the co-creation of human actors and the physical and social structures they inhabit, placing considerable emphasis on temporality and the continual process of that co-creation, in action. Reinvigorating apparently static and palimpsest archaeological patterns with some temporal dynamism has been a perennial problem (cf. Gardner 2012), but it can be achieved by taking the imaginative leap of viewing those patterns in terms of activities, charting the variation of those activities in terms of routines - or breaks from them - and then considering these as constituting different forms of power and identity. The potential for such approaches to unlock historically and culturally specific intersections of agency and structure is highlighted by their application in culture-contact situations. In a notable early study making explicit use of a practice framework, Kent Lightfoot, Antoinette Martinez, and Ann Schiff (1998) examined diachronic material and spatial patterns at Fort Ross, California, a Russian colony incorporating members of indigenous groups from California and Alaska. Focussing on interethnic households combining Alaskan men and Californian women, living within the structures of the Russian colonial authorities which superficially regulated many aspects of life, including identity categories, the authors chart how these structures were reproduced and transformed via daily routines. By examining the continuity and change in activities like food preparation and consumption, rubbish disposal, and everyday labour, persistent and novel traditions can be defined and linked to the specific historical agency of the people living in this location. More recently, my work on frontier regions in Roman Britain (Gardner 2017a, 2017b) compares regional patterns in boundarymaking and boundary-crossing practices. Similarly examining the evidence of everyday activities, I link the localisation of traditions in military and other sites to the political fragmentation of the later Roman state, against which trend considerable ideological effort was directed. This work explicitly addresses the materiality of practices as constituting dynamic agents and structures, and relates this to the political present, where the legacy of imperialism casts a long shadow over events like the EU referendum in the UK. Analysis of the dynamics of power and hierarchy in the Roman empire is surprisingly underdeveloped (cf. Fernández- 
Götz, Maschek and Roymans 2020), yet seems an ever more urgent project in the context of the contentious world in which we live.

These brief examples illustrate, I hope, some of the potential of archaeological applications of practice approaches, and there is much still to be mined, both within the specific bodies of theory that did enjoy some popularity in archaeology, like structuration theory, and others yet to be embraced. Thus, while Pragmatism in its classical sense has had very patchy attention in our discipline (e.g. Gaffney and Gaffney eds. 1987; Preucel and Mrozowski 2010; Preucel, this volume), its principles, as well as those of Marxism (McGuire, this volume), seem to me to offer ways of working on the problems outlined at the beginning of this paper, through working on our own labour, resolving some of the conditions of our fragmentation, and thus mobilising archaeology more effectively in the world today (e.g. Agbe-Davies 2018; McDavid 2000). I cannot see the same potential in post-humanist approaches, but I certainly respect the views of those who do, and the dialogue encapsulated in this Cambridge Archaeological Journal special issue is exactly what we need more of. Ultimately, there is not a universal paradigm which holds all of the answers for archaeology, because no such thing can satisfy all archaeologists. The important thing is that we get better at theoretical work in our discipline, furthering as much affinity for interdisciplinary projects as have been observed recently in more scientific domains (Nilsson Stutz 2018), and communicating readily across boundaries between theoretical traditions and, perhaps, even between ontologies. Listening to each other and working together to improve our theoretical practice would be a worthy response to the post-humanist challenge.

\section{Acknowledgements}

Many thanks to my special issue collaborators, Manuel Fernández-Götz, Guillermo Díaz de Liaño del Valle, and Oliver Harris, for shouldering many of the burdens in putting this collection together, and for advice on this paper - and also to the referees, and John Robb in the latter regard. Thanks also to numerous friends and colleagues, of diverse views on agency and post-humanism, for conversations which have contributed to this work, including Kerstin Hofmann, Matthew Johnson, Lisa Lodwick, Astrid Van Oyen, Bill Sillar and Tobias Kienlin.

\section{References}

Agbe-Davies, A.S. 2018. Laboring under an illusion: aligning method and theory in the archaeology of plantation slavery. Historical Archaeology 52: 125-139. 
Bentley, R.A., Lipo, C., Maschner, H.D.G., and Marler, B. 2008. Darwinian archaeologies. In R.A. Bentley, H.D.G. Maschner and C. Chippindale (eds.) Handbook of Archaeological Theories, 109-132. Walnut Creek: AltaMira Press.

Binford, L.R. 1981. Behavioural archaeology and the 'Pompeii premise'. Journal of Anthropological Research 37: 195-208.

Bloor, D. 1999. Anti-Latour. Studies in the History and Philosophy of Science 30(1): 81-112.

Caraher, W. 2019. Slow archaeology, punk archaeology, and the 'archaeology of care'. European Journal of Archaeology 22(3): 372-385.

Clarke, D.L. 1973. Archaeology: the loss of innocence. Antiquity 47: 6-18.

Dant, T. 1999. Material Culture in the Social World. Buckingham: Open University Press.

Dornan, J.L. 2002. Agency and archaeology: past, present, and future directions. Journal of Archaeological Method and Theory 9: 303-29.

Dunn, R.G. 1997. Self, identity and difference: Mead and the postructuralists. The Sociological Quarterly, 38(4): 687-705.

Elam, M. 1999. Living dangerously with Bruno Latour in a hybrid world. Theory, Culture \& Society 16(4): 1-24.

Emirbayer, M. and Mische, A. 1998. What is agency? American Journal of Sociology 103(4): 962-1023.

Fernández-Götz, M., Maschek, D. and Roymans, N. 2020. The dark side of the empire: Roman expansionism between object agency and predatory regime. Antiquity 94 (378), 163039.

Fewster, K. 2014. On practice. In A. Gardner, M. Lake and U. Sommer (eds) The Oxford Handbook of Archaeological Theory. Oxford: Oxford University Press.

Flannery, K.V. 1982. The golden Marshalltown: a parable for the archaeology of the 1980s. American Anthropologist 84: 265-78.

Gaffney, C.F. and Gaffney, V.L. (eds) 1987. Pragmatic Archaeology: theory in crisis? Oxford: B.A.R. British Series 167.

Gardner, A. 2003. Seeking a material turn: the artefactuality of the Roman empire. In G. Carr, E. Swift and J. Weekes (eds.) TRAC 2002: Proceedings of the 12th Annual Theoretical Roman Archaeology Conference, 1-13. Oxford: Oxbow Books.

Gardner, A. 2011. Action and structure in interpretive archaeologies. In E. Cochrane and A. Gardner (eds.) Evolutionary and Interpretive Archaeologies. A dialogue, 63-82. Walnut Creek: Left Coast Press. 
Gardner, A. 2012. Time and empire in the Roman world. Journal of Social Archaeology 12.2, 145-66.

Gardner, A. 2016. Debating Roman imperialism: critique, construct, repeat? In M.J. Mandich, T.J. Derrick, S. Gonzalez Sanchez, G. Savani and E. Zampieri (eds) TRAC 2015: Proceedings of the 25th Annual Theoretical Roman Archaeology Conference, 1-14. Oxford: Oxbow Books.

Gardner, A. 2017a. Brexit, boundaries, and imperial identities - a comparative view. Journal of Social Archaeology, 17.1, 3-26.

Gardner, A. 2017b. Roman Britain from the outside: comparing western and northern frontier cultures. In S. González Sánchez and A. Guglielmi (eds.) 'Romans' and 'Barbarians' beyond the Frontiers: Archaeology, ideology and identities in the North, 34-47. Oxford: Oxbow Books (TRAC Research Papers).

Hegmon, M. 2003. Setting theoretical egos aside: issues and theory in North American archaeology. American Antiquity 68: 213-43.

Hodder, I. 1985. Post-processual archaeology. In M. Schiffer (ed.) Advances in Archaeological Method and Theory, Vol. 8, 1-26. New York: Academic Press.

Johnson, M. 2006. On the nature of theoretical archaeology and archaeological theory. Archaeological Dialogues 13(2): 117-32.

Johnson, M. 2020. Archaeological Theory: an Introduction ( $3^{\text {rd }}$ edition). Oxford: WileyBlackwell.

Jones, M.P. 1996. Posthuman agency: between theoretical traditions. Sociological Theory 14(3): 290-309.

Joyce, R.A. and Lopiparo, J. 2005. Postscript: doing agency in archaeology. Journal of Archaeological Method and Theory 12(4): 365-374.

Kristiansen, K. 2014. Towards a new paradigm? The third science revolution and its possible consequences in archaeology. Current Swedish Archaeology 22: 11-34.

Lightfoot, K.G., Martinez, A. and Schiff, A.M. 1998. Daily practice and material culture in pluralistic social settings: an archaeological study of culture change and persistence from Fort Ross, California. American Antiquity 63(2): 199-222.

Lindstrøm, T.C. 2015. Agency 'in itself'. A discussion of inanimate, animal and human agency. Archaeological Dialogues 22(2): 207-238.

Lucas, G. 2015. The mobility of theory. Current Swedish Archaeology 23, 13-32.

Matthewman, S. 2011. Technology and Social Theory. Basingstoke: Palgrave Macmillan. 
McCarthy, E.D. 1984. Towards a sociology of the physical world: George Herbert Mead on physical objects. Studies in Symbolic Interaction 5: 105-121.

McDavid, C. 2000. Archaeology as cultural critique: Pragmatism and the archaeology of a southern United States plantation, with a comment by L. Daniel Mouer. In C. Holtorf and H. Karlsson (eds) Philosophy and Archaeological Practice: Perspectives for the 21st Century, 221-239. Göteborg: Bricoleur Press.

Mead, G.H. 2002. The Philosophy of the Present. Amherst: Prometheus Books.

Mizoguchi, K. 2015. A future of archaeology. Antiquity 89 (343): 12-22.

Nicolini, D. 2012. Practice Theory, Work, and Organization: an introduction. Oxford: Oxford University Press.

Nilsson Stutz, L. 2018. A future for archaeology: in defense of an intellectually engaged, collaborative and confident archaeology. Norwegian Archaeological Review 51(1/2): 48-56.

O’Brien, M.J., Lyman, R.L. and Schiffer, M.B. 2005. Archaeology as a Process: Processualism and its progeny. Salt Lake City: University of Utah Press.

Olsen, B., Shanks, M., Webmoor, T. and Witmore, C. 2012. Archaeology: the discipline of things. Berkeley: University of California Press.

Orlikowski, W.J. 2000. Using technology and constituting structures: a practice lens for studying technology in organizations. Organization Science 11(4): 404-428.

Preda, A. 1999. The turn to things: arguments for a sociological theory of things. The Sociological Quarterly 40(2): 347-366.

Preucel, R.W. and Mrozowski, S.A. 2010. The new pragmatism. In R.W. Preucel and S.A. Mrozowski (eds) Contemporary Archaeology in Theory: the new pragmatism, 3-49. Chichester: Wiley-Blackwell.

Reckwitz, A. 2002. Toward a theory of social practices: a development in culturalist theorizing. European Journal of Social Theory 5(2): 243-263.

Ribeiro, A. 2016. Against object agency. A counterreaction to Sorensen's 'Hammers and nails'. Archaeological Dialogues 23(2): 229-235.

Ribeiro, A. 2018. Death of the passive subject: intentional action and narrative explanation in archaeological studies. History of the Human Sciences 31(3): 105-121.

Rosenzweig, M.S. 2020. Confronting the present: archaeology in 2019. American Anthropologist 122(2): 284-305. 
Saitta, D.J. 2003. Archaeology and the problems of men. In T.L. VanPool and C.S. VanPool. (eds) Essential Tensions in Archaeological Method and Theory, 11-15. Salt Lake City: University of Utah Press.

Schatzki, T.R. 2006. Introduction: practice theory. In T.R. Schatzki, K. Knorr Cetina and E. von Savigny (eds) The Practice Turn in Contemporary Theory, 1-14. London: Routledge.

Schatzki, T. 2010. Materiality and social life. Nature and Culture 5(2): 123-149.

Schiffer, M. B. 1985. Is there a 'Pompeii premise' in archaeology? Journal of Anthropological Research 41: 18-41.

Shalin, D.N. 2000. George Herbert Mead. In G. Ritzer (ed.) The Blackwell Companion to Major Social Theorists, 302-44. Oxford: Blackwell.

Shanks, M. 2008. Post-processual archaeology and after. In R.A. Bentley, H.D.G. Maschner and C. Chippindale (eds.) Handbook of Archaeological Theories, 133-44. Walnut Creek: AltaMira Press.

Simpson, B. 2009. Pragmatism, Mead and the practice turn. Organization Studies 30: 13291347.

Van Dyke, R.M. 2015. Materiality in practice: an introduction. In R.M. Van Dyke (ed.) Practicing Materiality, 3-32. Tucson: University of Arizona Press.

Vandenberghe, F. 2002. Reconstructing humants: a humanist critique of Actant-Network Theory. Theory, Culture \& Society 19(5/6): 51-67.

Wenger, E. 1998. Communities of Practice: learning, meaning, and identity. Cambridge: Cambridge University Press.

Wheeler, R.E.M. 1954. Archaeology from the Earth. Oxford: Clarendon Press.

White, H. 2013. Materiality, form, and context: Marx contra Latour. Victorian Studies 55(4): 667-682. 